\title{
Residential Environment Induced Preference Heterogeneity for River Ecosystem Service Improvements: A Comparison between Urban and Rural Households in the Wei River Basin, China
}

\author{
Hengtong Shi, Minjuan Zhao, Fanus Asefaw Aregay, Kai Zhao, and Zhide Jiang \\ College of Economics \& Management, Northwest A\&F University, Yangling, Shaanxi 712100, China \\ Correspondence should be addressed to Minjuan Zhao; minjuan.zhao@nwsuaf.edu.cn
}

Received 17 October 2015; Accepted 5 January 2016

Academic Editor: Binggen Zhang

Copyright (C) 2016 Hengtong Shi et al. This is an open access article distributed under the Creative Commons Attribution License, which permits unrestricted use, distribution, and reproduction in any medium, provided the original work is properly cited.

\begin{abstract}
This paper assesses residential environment induced preference heterogeneity regarding ecosystem services improvements of a river basin by comparing urban and rural residents' welfare estimates. In a choice experiment, the ecological improvements are described in terms of several observable ecological indicators set in an experimental design. Given the fact that economic and environmental conditions differ for urban and rural residents in China, the utility they derive from ecological restoration is hypothesized to differ. The urban and rural residents' survey data were modeled separately using mixed logit models. The results reveal that water quality and water quantity, measured by unit of level improvement and percentage improvement, respectively, hold the highest marginal utility values in all respondents' models. Urban and rural residents have the same preference regarding expanding soil erosion control areas and landscape improvement. However, they have statistically significant different utility for water quality, water quantity, forest coverage, ecotourism improvements, and reducing soil erosion intensity. Generally, urban residents express a higher implicit price for most of the ecological indicators. The findings imply that policy makers should take existing preference heterogeneity into account in designing ecosystem payment schemes and allocating resources.
\end{abstract}

\section{Introduction}

Through economic development and excessive human disturbance, ecosystem degradation has become a worldwide environmental problem, and China is not alone in experiencing serious environmental and ecological crises. As a remedy for the escalating flooding, soil erosion, and habitat losses, the Chinese government has introduced a series of ecological restoration policies including the Sloping Land Conversion Program, the National Forest Protection Program, and the Desertification Combating Program around Beijing and Tianjin District since the late 1990s [1]. These programs have actually improved the ecological environment to a certain extent and earned China a reputation around the world [2]. However, there still remain many questions on whether the restoration policies have been effectively implemented and how their performance can be improved. Public participation in environmental management issues such as ecological restoration is becoming more and more significant in the development of China's healthy environmental governance system [3]. However, payment schemes relevant to the restoration policies are seriously constrained by a lack of knowledge regarding the demand for ecosystem services of the Chinese community $[4,5]$.

The mismatch between supply and demand of ecosystem services may lead to low efficiency in ecological restoration programs. The ecosystem often supplies people with different kinds of benefits such as provisioning, regulating, supporting, and cultural services [6]. Restoration programs and ecosystem managers often promote those provisioning services with high market value to the detriment of other services (nonmarket values) that are less visible but equally important. On the other hand, on the demand side, people may have strong preferences for various ecosystem services, including those with nonmarket value. Accounting for preference heterogeneity may alleviate the mismatch between public demand and ecological restoration program outcomes. Besides accounting for public preference heterogeneity in 
different aspects, this paper argues that the ecological restoration payment schemes for rural and urban residents should be different. The dual economic structure in China has widened the income difference between urban and rural areas [7], and this is expected to lead to substantial differences between urban and rural residents with regard to their preferences for ecosystem service improvements. Both urban and rural residents may benefit directly and/or indirectly from different aspects (attributes) of use and nonuse values improving ecosystem services. Given the existing differences in socioeconomic status and lifestyle between the two groups, welfare values as measured by the heterogeneity in the willingness of households to pay for the different attributes of ecological restoration are expected to differ.

There is a growing literature concerning ecosystem service improvements which reflects increasing recognition of the importance of preference heterogeneity. Birol et al. [8] employed a choice experiment approach to assess preference heterogeneity in estimating changes in welfare produced by some ecological, social, and economic functions the Cheimaditida wetland provides to the Greek public; Colombo et al. [9] modeled preference heterogeneity in stated choice data in analyzing public goods generated by agriculture in the northwest region of England. The study incorporated heterogeneity in preferences through both the systematic and the random component of utility (for the systematic component of utility, both a random parameter logit model and a latent class model are employed, and for the random component of utility, error component models are utilized to characterize preference heterogeneity [see details in Colombo et al. [9]]). Brouwer et al. [10] investigated spatial preference heterogeneity by testing the hypothesis that people living in a river basin value water quality improvements differently depending on where they live. They carried out a case study in the Guadalquivir River basin in the south of Spain and found that not accounting for spatial preference heterogeneity results in underestimation of welfare values. Abildtrup et al. [11] analyzed preference heterogeneity in the recreational use of forest in Lorraine (Northeastern France) by applying a choice experiment, with the study testing whether preferences depend on access to recreation sites. Generally, these studies compare welfare values of different groups of people living in different integral parts of the river basin or who have different distances from the resources and improvement sites but give no attention to preference heterogeneity due to different living environments.

Though numerous previous studies have discussed spatial preference heterogeneity concerning ecological restoration issues such as water quality and forest recreation improvements $[10,11]$, little is known about preference heterogeneity between different groups of people living within the same area. The aim of the present paper is to investigate the differences between urban and rural households in marginal willingness to pay for different ecological river basin improvement attributes. The findings are expected to have significant policy implications since residential environment related preference heterogeneity is commonly ignored when ecosystem restoration programs are implemented in China.
The paper is organized as follows. Section 2 describes the case study area. Section 3 introduces the choice experiment approach as a tool for welfare measurement. Section 4 provides a description of the survey design, followed by empirical results in Section 5. Section 6 presents discussion and conclusions.

\section{Case Study Area}

The Wei River is the largest tributary of the Yellow River, located in the arid and semiarid area in northwest China, and flows across three geographic units including the Loess plateau, the Guanzhong Basin, and the North Qinling Mountains. The Guanzhong area in Shaanxi province lies in the middle and lower reaches of the Wei and accounts for $50 \%$ of the total area of the Wei basin (see the map in Figure 1). With its fertile soil and well-developed irrigation system, the Guanzhong area plays a vital role in food production in China. However, with the rapid economic development over the last thirty years, the environmental problems are escalating with the increasing utilization of water resources. According to a government document, the Wei River Key Governance Plan [12], the main environmental problems which restrict the sustainable development of the Wei River basin are as follows: (1) frequent flooding in the middle reaches and downstream depositing large amounts of sediments and old and poor quality dams making flood protection more difficult; (2) serious water shortages as the total runoff of the Wei River basin, which amounts to about 10.04 billion $\mathrm{m}^{3}$, equals only $308 \mathrm{~m}^{3}$ per person, and accounts for $13 \%$ of the average national quantity of water per capita (increasing diversion of water for urban and industrial water use is inhibiting irrigation and ecological water use; furthermore, overexploitation of groundwater is leading to the deterioration of the ecological environment); (3) the total amount of waste water discharged into the Wei River basin (originating largely from major cities like Baoji, Xianyang, Xian, and Weinan) which is increasing sharply (moreover, many industrial pollution treatment devices have not been used effectively; thus large amounts of waste water flow directly into the river without being processed); (4) the destruction of vegetation which is exacerbating soil erosion and more areas which need to be protected to mitigate this.

The potential for Chinese communities to benefit from the environmental improvements in the Wei River basin remains largely unexplored. The importance of evaluating the welfare benefits of ecosystem services is vital. If we fail to value these services, the economic systems we rely on will remain biased toward ecosystem degradation and overexploitation. The welfare benefit estimate can further be used in cost benefit analysis (CBA) of the Wei River Governance Projects. Furthermore, the valuation results can be used in benefit transfer analysis in assessing the welfare values of water resource management projects in other analogous river basins.

\section{The Choice Experiment Approach}

The choice experiment (CE) is one kind of stated preference method used in environmental economics and ecological 


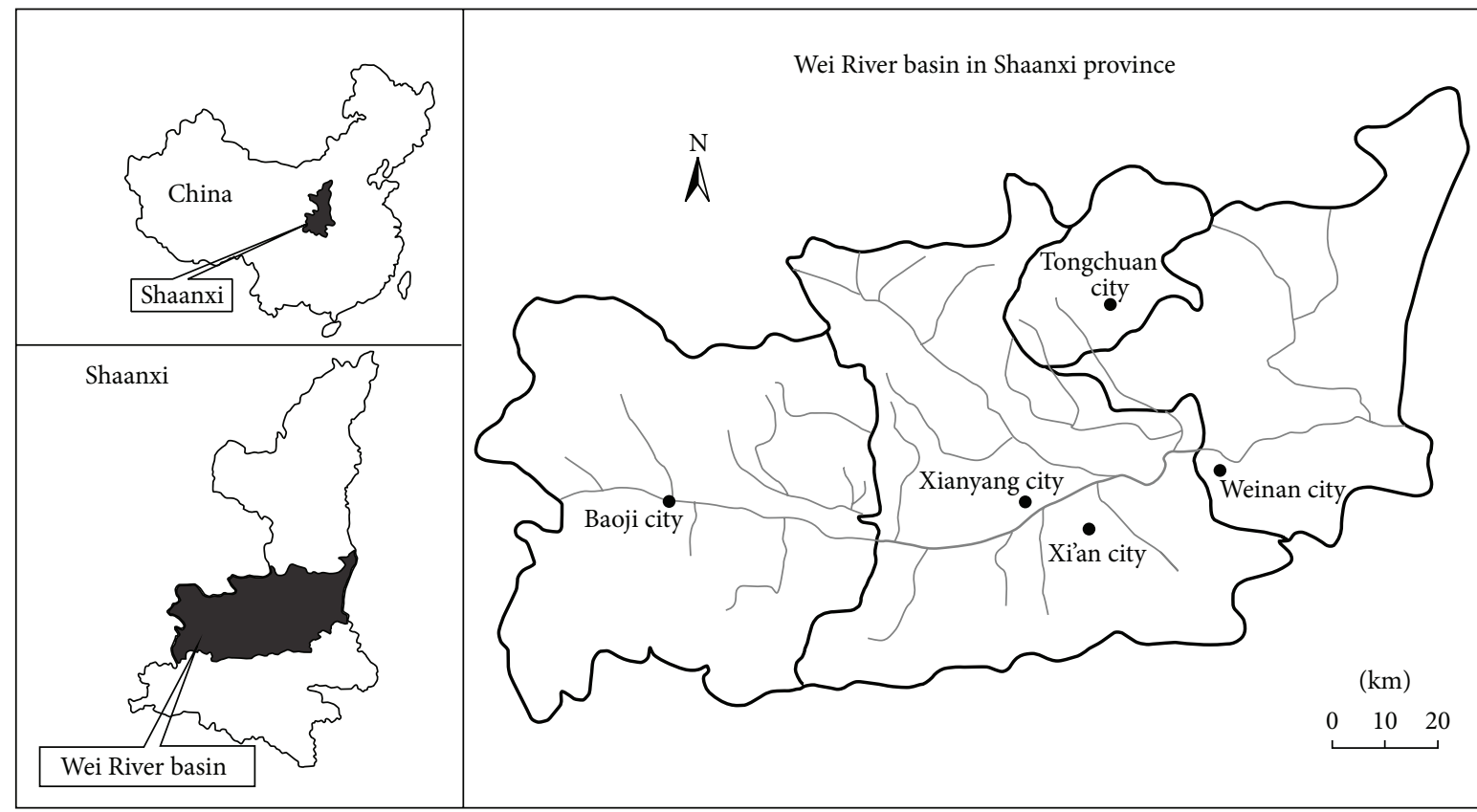

- Government station Watershed boundary

— Urban boundary
$\Downarrow$ River

FIgURE 1: Map of the Wei River basin in Shaanxi province, China.

economics. It allows respondents' most preferred management options to be surveyed from a range of potential alternative environmental management strategies. The researcher can then estimate the nonmarket values of these public goods by measuring the mean willingness to pay (WTP) of respondents. As with any stated preference method, a choice experiment is built on the behavioral foundation of the following two theories: (1) Lancastrian consumer theory [13] which proposes that consumers' utilities can be divided into separate utilities, the consumers' characteristics, and attributes of the consumer good or service; (2) random utility theory which forms the basis of theories of consumer judgment and decision making in both psychology and economics [14-17]. Variations in choice can be explained by proposing a random component of consumer's utility function. That is,

$$
U_{i}=V_{i}+\varepsilon_{i},
$$

where $U_{i}$ is the unobservable, true utility for option $i, V_{i}$ is the systematic, observable component of utility, and $\varepsilon_{i}$ is the random, unexplained component. For all available $j$ options, the probability that a given respondent chooses option $i$ can be expressed as

$$
P(i)=\operatorname{Pr}\left[U_{i}>U_{j}\right]=\operatorname{Pr}\left[\left(V_{i}+\varepsilon_{i}\right)>\left(V_{j}+\varepsilon_{j}\right)\right] .
$$

For the systematic component, the simplest function form relating the attributes of the choice sets is a linear one as follows:

$$
V_{i}=C+\beta^{\prime} X_{i}
$$

where $C$ is the alternative specific constant (ASC). $\beta^{\prime}$ is a vector of utility coefficients associated with a vector $X$ of explanatory variables (including household charges, environmental restoration attributes, population characteristics, and even interactions between these elements).

Different probabilistic choice models can be derived by making different assumptions about the distribution of error term (random component). For instance, a bivariate normal distribution leads to the binary probit model [14], and a Gumbel distribution gives rise to the conditional or multinomial logit (MNL) model $[15,18]$. The more popular mixed logit model or random parameter logit (RPL) model gives a full relaxation of the independence of irrelevant alternatives (IIA) assumption in MNL and allows model parameters to vary randomly over individuals $[19,20]$. The coefficients vary over respondents in the population with density $f(\beta)$. This density is a function of parameters $\theta$ that represent, for example, the mean and covariance of $\beta$ 's in the population. The mixed logit probability is

$$
P_{n i}=\int \frac{e^{\beta X_{n i}}}{\sum_{j} e^{\beta X_{j}}} f(\beta) d \beta .
$$

This specification is the same as that for standard logit except that $\beta$ varies over decision makers rather than being fixed.

The results expected from the CE should be informative because they reflect tradeoffs that respondents are willing to make among and between the environmental attributes and household costs, measured as the WTP (if referring to 
TABLE 1: Levels of different valuation indicators.

\begin{tabular}{|c|c|c|c|c|}
\hline Valuation indicators & Status quo & \multicolumn{2}{|c|}{ Alternative levels } & Target level \\
\hline Percentage of forest coverage & $30 \%$ & $31 \%$ & $33 \%$ & $35 \%$ \\
\hline Average water quality level & Level 4.5 & Level 4 & Level 3.5 & Level 3 \\
\hline Water quantity per person (percentage of average level in China) & $15 \%$ & $17 \%$ & $19 \%$ & $20 \%$ \\
\hline Soil erosion controlling area (percentage) & $80 \%$ & $85 \%$ & $88 \%$ & $90 \%$ \\
\hline Soil erosion intensity & Moderate $(=3)$ & \multicolumn{2}{|c|}{ Partially mild $(=2)$} & Mild (=1) \\
\hline Natural landscapes & $20 \%$ & $30 \%$ & $35 \%$ & $40 \%$ \\
\hline Percentage of ecotravel, forest parks & $25 \%$ & \multicolumn{2}{|c|}{$30 \%$} & $35 \%$ \\
\hline Cost & 50 & 100 & 200 & 300 \\
\hline
\end{tabular}

the tradeoff between an attribute and a cost) and marginal rate of substitution (if referring to the tradeoff between two attributes). WTP or implicit price, our core interest in this paper, can be interpreted in

$$
\mathrm{IP}=-\frac{\beta_{n m}}{\beta_{M}},
$$

where $\beta_{M}$ is the marginal utility of income (assumed to be equal to the coefficient of the cost attribute); $\beta_{n m}$ is the parameter of one environmental attribute. The attribute and cost coefficients are to be estimated using the mixed logit model.

\section{Survey Design}

4.1. CE Survey Design. Based on the research of Daily [21], Costanza et al. [22], and de Groot et al. [23], ecosystem services (ES) are classified into four types: regulating service, habitat service, production service, and information service. The CE in the Wei River was carefully designed to include relevant ecological attributes keeping these four complements of the ecosystem in mind.

The ecological attributes are then explained in terms of closed related valuation indicators that are more visible and intuitive to interviewees. The indicators not only are expected to affect respondents' choices, but also are policy relevant. Based on a literature review of the current ecological situation of the Wei River and consulting ecological and hydrological experts, eight indicators (seven ecological attributes and one household payment) are selected as given in Table 1. Two pilot surveys were conducted prior to the final questionnaire design in order to test the cognitive complexity to respondents given the tradeoff with omitted indicator bias. Among all the indicators, the average levels of water quality and water quantity per person are related to the production service in ecosystem services, the soil erosion control area and soil erosion intensity correspond to the regulating service, natural landscape and percentage of ecotravel, as well as forest parks, are linked to the information service, and the percentage of forest coverage falls under the habitat service.

The values for the status quo and the maximum possible improvement levels (after ten years) were set based on the Wei River Key Governance Plan [12] reports on the current situation and ten-year target values. We then include the interval levels to make the choice smooth and acceptable.
The levels for the cost attributes designed to have normal distribution are based on feedback from the pilot surveys. The final levels of different indicators are shown in Table 1.

The choice sets of the choice experiment were carefully designed to produce efficient welfare measurement. For precise parameter estimates in a linear model, a D-optimal orthogonal design was used to design the choice alternatives using "SAS" software [24, 25]. 512 choice sets were produced, composed of one status quo and two scenario options similar to the typical example in Table 2. After clearing for dominant and unreliable sets, 450 were grouped into 150 booklets with 3 choice tasks in each.

Each respondent was asked to choose his/her preferred alternative (from three alternatives in a given choice set; two policy options and one status quo option) and each one had three independent choice tasks in total. The respondents were informed that the household charge related to the policy alternatives was compulsory. They were told that this was a compulsory annual payment for a 10 -year period which would go into a special fund to be used only for environmental improvement in the Wei River basin.

4.2. Sample Description. The CE survey was conducted in the winter of 2012. Eight trained postgraduate students who majored in agricultural and resources economics were sent to carry out the survey based on a face-to-face interview with sample residents of Wei River basin, Shaanxi province. The sample selection involved three stages. First, the basin Shaanxi section was divided into three based on the difference on current local water quality followed by the random selection of a county from each category, resulting in a total of four counties. Then, within each county, residents were categorized into two groups as urban and rural households (Table 3). Finally, stratified random sampling was employed to select sample representatives from each group. Urban households were randomly chosen from three communities in three residential districts. Similarly, rural households were randomly chosen from three villages in three townships. Within each community or village, twelve to fourteen households were randomly chosen. Finally, a total of 900 households were contacted.

The sociodemographics of the respondents are shown in Table 4. On average, rural respondents are more frequently male and older than urban respondents. This is expected because most of the younger generations in China leave 
TABLE 2: A typical example of a choice set in the choice experiment.

\begin{tabular}{|c|c|c|c|}
\hline Indicators & Status quo & Option 1 & Option 2 \\
\hline Percentage of forest coverage & $30 \%$ & $31 \%(+1 \%)$ & $33 \%(+3 \%)$ \\
\hline Average water quality level in the river basin & Level 4.5 & Level 4 & Level 4.5 \\
\hline Water quantity per person in the basin compared to the national level & $15 \%$ & $15 \%(+0 \%)$ & $17 \%(+2 \%)$ \\
\hline Soil erosion controlling area (percentage) & $80 \%$ & $90 \%(+10 \%)$ & $88 \%(+8 \%)$ \\
\hline Soil erosion intensity & Moderate $(=3)$ & Partially mild $(=2)$ & Mild (=1) \\
\hline Natural landscapes & $20 \%$ & $30 \%(+10 \%)$ & $20 \%(+0 \%)$ \\
\hline Percentage of ecotravel, forest parks & $25 \%$ & $25 \%(+0 \%)$ & $35 \%(+10 \%)$ \\
\hline Cost to your household per year & 0 & $100 \mathrm{RMB}$ & $100 \mathrm{RMB}$ \\
\hline Mark your preferred alternative & $\square$ & $\square$ & $\square$ \\
\hline
\end{tabular}

Note: water quality level: level 2: relatively clean, can be used for drinking after conventional purification; level 3: can be used for centralized domestic water, fishing water, or swimming water; level 4: can be used for industrial and agricultural water, cannot be used for drinking, swimming, and fishery; level 5: not suitable for any use.

TABle 3: Sample distribution.

\begin{tabular}{lccc}
\hline & Urban households & Rural households & Total \\
\hline Jin Tai & 110 & 115 & 225 \\
Qin Du & 100 & 125 & 225 \\
Lin Wei & 102 & 120 & 222 \\
Hua Yin & 115 & 113 & 228 \\
Total & 427 & 473 & 900 \\
\hline
\end{tabular}

their villages to search for jobs in the cities. Similarly, family size is larger in rural areas because extended families and having more children are more widespread. The mean income and household head education level are higher for urban residents due to better access to education and professional jobs compared to rural residents. All the differences in their sociodemographic characteristics combined with the differences in ecological environments may lead to the differences in WTP of urban and rural households.

\section{Results}

5.1. Ecological Perceptions. Table 5 shows the sample's perceptions of the ecological environment. In the introductory part of the questionnaire, each interviewee was asked to rank the 9 ecological attributes based on the importance to them $(1=$ the most important, 2 = the second important, .., $9=$ the least important). As the results illustrate, residents care most strongly about water quantity and quality (with the mean rank value of 1.93 and lowest standard deviation of 1.66). Agricultural and industrial water, soil erosion control, and vegetation restoration, respectively, were the next most important aspects to the residents, while the remaining attributes are perceived as relatively less important with a mean rank of above 6 . Within the 900 sample representatives, 62 percent (558 residents) chose "water quantity and quality" as the most important indicator, and about 36 percent (321 residents) chose "recreation" as the least important indicator. In general, residents living in the Wei River basin care more about the ecological indicators related to the environment and pay more attention to the use value of the watershed ecosystem.

5.2. The Mixed Logit Model. The mixed logit model estimated the pooled dataset and rural and urban residents subgroups using the Stata software version 12.0. All the models assumed normal distribution, with all attributes specified as random variables except the cost attribute (it is convenient to set the cost coefficient as fixed for the reason that the distribution of an ecological indicator's coefficient is simply the same as the distribution of the marginal WTP for that indicator) and specified 500 Halton draws. No constraint is enforced on the signs of the random parameters of the ecological indicators following Train [26] and Hole [27]. The results of the mixed logit model estimations are given in Table 6.

All the mean parameters have at least a $5 \%$ significance level in all the three mixed logit models. They have expected signs. Positive mean coefficients for most of the random parameters indicate that all respondents, both urban and rural residents, show general consensus with regard to all the indicators, and they prefer the "improvement" to status quo scenarios in general. The improvement is measured by a positive change in forest coverage, water quantity, soil erosion control area, landscape increase, and the percentage of ecotourism and forest parks. The negative mean coefficients for water quality level and soil erosion are related to the measurement unit, with the lower values being preferred, while the expected negative mean coefficient of cost implies the positive utility of money held by the residents. Respondents prefer more of the improvement attributes given the same cost. All the standard deviations of the random parameters are statistically significant, suggesting that there is substantial preference heterogeneity among respondents. It seems that separating urban residents and rural residents is a better choice. With the separated models, the standard deviations of random parameters are smaller and the standard errors of variables are also smaller.

The interpretation and comparison of the coefficients of ecological attributes have to be made with caution because the unit of measurement differs. Water quality and soil erosion 
TABLE 4: Sociodemographics of the respondents.

\begin{tabular}{|c|c|c|c|c|c|c|}
\hline \multirow{2}{*}{ Variable } & \multicolumn{2}{|c|}{ Pooled sample } & \multicolumn{2}{|c|}{ Urban households } & \multicolumn{2}{|c|}{ Rural households } \\
\hline & Mean & Std. Dev. & Mean & Std. Dev. & Mean & Std. Dev. \\
\hline Gender $($ male $=1$, female $=0)$ & 0.58 & 0.49 & 0.45 & 0.50 & 0.69 & 0.46 \\
\hline Age (years) & 42.26 & 13.20 & 36.53 & 11.76 & 47.25 & 12.20 \\
\hline Education & 2.89 & 1.22 & 3.66 & 1.12 & 2.24 & 0.89 \\
\hline Household size & 4.32 & 2.38 & 3.78 & 1.24 & 4.79 & 2.96 \\
\hline Household income (thousand CNY per year) & 53.97 & 55.08 & 65.03 & 64.70 & 44.51 & 43.14 \\
\hline Sample size, $N$ & \multicolumn{2}{|c|}{900} & \multicolumn{2}{|c|}{427} & \multicolumn{2}{|c|}{473} \\
\hline
\end{tabular}

Note: educational level of head of household was measured in 5 categories: (1) primary school or below; (2) junior middle school; (3) senior high school; (4) junior college; (5) bachelor degree or above.

TABLE 5: Summary of ecological perceptions $(n=900)$.

\begin{tabular}{|c|c|c|c|}
\hline Ecological indicator & Definition & Mean & Std. Dev. \\
\hline Water quantity \& quality & Water quantity and quality in the river basin & 1.93 & 1.66 \\
\hline Agricultural \& industrial water & Water resources that support agricultural and industrial production & 3.30 & 2.16 \\
\hline Soil erosion controlling & Preventing bare soil from being washed away & 3.85 & 2.29 \\
\hline Vegetation restoration & Increasing forest, grassland, bush, and so on & 4.32 & 1.89 \\
\hline Habitat & Providing suitable living space for wildlife animals & 6.16 & 1.79 \\
\hline Breeding and migration & Providing places for animals to breed and migrate & 6.61 & 1.73 \\
\hline Wildlife species & Increasing species of healthy wildlife animals & 6.20 & 1.82 \\
\hline Enjoying the scenery & Increasing special landscapes of scenic appeal & 6.08 & 2.27 \\
\hline Recreation & Providing places for ecotravelling, fishing, and outdoor activities & 6.55 & 2.48 \\
\hline
\end{tabular}

TABLE 6: Mixed logit model results.

\begin{tabular}{|c|c|c|c|}
\hline Variables & $\begin{array}{l}\text { All respondents } \\
\text { (pooled dataset) }\end{array}$ & $\begin{array}{c}\text { Urban residents } \\
\text { (subgroup) }\end{array}$ & $\begin{array}{c}\text { Rural residents } \\
\text { (subgroup) }\end{array}$ \\
\hline \multicolumn{4}{|c|}{ Nonrandom parameter } \\
\hline Cost & $-0.0421^{* * *}(0.0079)$ & $-0.0213^{* * *}(0.0032)$ & $-0.0321^{* * *}(0.0050)$ \\
\hline \multicolumn{4}{|c|}{ Mean (standard errors) of random parameters } \\
\hline Forest coverage & $0.4090^{* * *}(0.1036)$ & $0.2822^{* * *}(0.0652)$ & $0.1966^{* *}(0.0908)$ \\
\hline Water quality & $-3.7431^{* * *}(0.7648)$ & $-2.5160^{* * *}(0.4421)$ & $-2.4641^{* * *}(0.6179)$ \\
\hline Water quantity & $0.4715^{* * *}(0.1183)$ & $0.3441^{* * *}(0.0825)$ & $0.2589^{* * *}(0.0951)$ \\
\hline Erosion area & $0.1610^{* * *}(0.0442)$ & $0.1000^{* * *}(0.0268)$ & $0.1052^{* *}(0.0425)$ \\
\hline Erosion intensity & $-1.0143^{* * *}(0.2249)$ & $-0.7877^{* * *}(0.1355)$ & $-0.4738^{* *}(0.1879)$ \\
\hline Landscape & $0.1347^{* * *}(0.0296)$ & $0.0646^{* * *}(0.0155)$ & $0.1213^{* * *}(0.0261)$ \\
\hline Tour & $0.1115^{* * *}(0.0358)$ & $0.0493^{* *}(0.0247)$ & $0.1439^{* * *}(0.0368)$ \\
\hline \multicolumn{4}{|c|}{ Standard deviation of random parameters } \\
\hline Forest coverage & $1.0367^{* * *}(0.2373)$ & $0.5546^{* * *}(0.1051)$ & $0.8733^{* * *}(0.1894)$ \\
\hline Water quality & $6.3408^{* * *}(1.0858)$ & $3.5856^{* * *}(0.4384)$ & $4.6882^{* * *}(0.6362)$ \\
\hline Water quantity & $1.1997^{* * *}(0.2552)$ & $0.5862^{* * *}(0.1105)$ & $0.8576^{* * *}(0.1816)$ \\
\hline Erosion area & $0.4963^{* * *}(0.0978)$ & $0.3124^{* * *}(0.0577)$ & $0.3401^{* * *}(0.0843)$ \\
\hline Erosion intensity & $1.6762^{* * *}(0.3697)$ & $0.6448^{* *}(0.2883)$ & $1.7565^{* * *}(0.3276)$ \\
\hline Landscape & $0.1775^{* * *}(0.0381)$ & $0.0500^{*}(0.0301)$ & $0.1333^{* * *}(0.0381)$ \\
\hline Tour & $0.4512^{* * *}(0.0861)$ & $0.2586^{* * *}(0.0494)$ & $0.2966^{* * *}(0.0660)$ \\
\hline \multicolumn{4}{|c|}{ Model statistics } \\
\hline Log-likelihood (LL) & -2355.8853 & -1158.7675 & -1197.8596 \\
\hline Pseudo- $R^{2}$ & 0.1167 & 0.0999 & 0.1169 \\
\hline Number of obs. & 900 & 427 & 473 \\
\hline
\end{tabular}

Note: $*, * *$, and $* * *$ denote significance at $10 \%, 5 \%$, and $1 \%$ level, respectively. 
TABLE 7: Implicit prices of the mixed logit models and confidence intervals (95\% level).

\begin{tabular}{lccc}
\hline Indicators & All respondents & Urban residents & Rural residents \\
\hline Forest coverage & $9.71^{* * *}(6.51-12.91)$ & $13.22^{* * *}(8.23-18.22)$ & $6.13^{* *}(1.14-11.13)$ \\
Water quality & $-88.84^{* * *}(-102.34$ to -75.35$)$ & $-117.88^{* * *}(-139.11$ to -96.65$)$ & $-76.87^{* * *}(-100.34$ to -53.39$)$ \\
Water quantity & $11.19^{* * *}(7.76-14.62)$ & $16.12^{* * *}(10.99-21.26)$ & $8.08^{* * *}(3.17-12.99)$ \\
Erosion area & $3.82^{* * *}(2.26-5.38)$ & $4.68^{* * *}(2.27-7.10)$ & $3.28^{* * *}(0.90-5.66)$ \\
Erosion intensity & $-24.07^{* * *}(-30.90$ to -17.25$)$ & $-36.90^{* * *}(-48.67$ to -25.14$)$ & $-14.78^{* * *}(-25.63$ to -3.94$)$ \\
Landscape & $3.20^{* * *}(2.46-3.93)$ & $3.03^{* * *}(1.97-4.08)$ & $3.78^{* * *}(2.82-4.75)$ \\
Tour & $2.65^{* * *}(1.24-4.06)$ & $2.31^{* *}(0.09-4.53)$ & $4.49^{* * *}(2.53-6.45)$ \\
\hline
\end{tabular}

Note: $* *$ and $* * *$ denote significance at $5 \%$ and $1 \%$ level, respectively; confidence intervals are in parentheses.

intensity are measured in the same index. All the models have a higher mean coefficient for water quality, indicating water quality is relatively important to the residents. All the other ecological indicators are measured in percentages. Generally, water quantity has highest mean coefficient value while tour (ecotourism and forest parks) was valued lowest among these attributes. All the standard errors of urban residents are smaller than those of rural residents, for both fixed and random parameters.

5.3. Willingness to Pay (WTP) or Implicit Price Measures. Since cost is assumed to be a fixed parameter, implicit prices can be estimated using the welfare simulation following the general approach of Hensher and Greene [28]. Given the model coefficients, implicit prices are calculated based on formula in (5) above. The estimated implicit prices derived from the three mixed logit models are displayed in Table 7. The implicit prices show the mean annual WTP of a given respondent for one unit of improvement in the ecological indicator for a period of 10 years.

In other words, the implicit price for any given attribute is the marginal WTP for one unit increase in that ecological indicator, holding others constant. For example, water quality has the implicit price of -88.84 in the model of pooled responses, which means that people would be ready to pay CNY 88.84 (USD 14.53) (we use the exchange rate of 6.1115 (CNY 1 = USD 0.1636), also in the following calculations) per year over the following 10 years for a one-level improvement in water quality per household (e.g., from level 4 to level 3). Water quantity holds an implicit price of CNY 11.19, which means respondents would be prepared to pay CNY 11.19 (USD 1.83) each year for the following 10 years for a one percent increase in water quantity compared to the national water level per household (such as from $15 \%$ to $16 \%$ of China's average).

An equality of the WTP for the attributes across the three models was tested following Poe et al. [29]. It was carried out to determine whether there are significant differences between the urban and rural residents in the implicit prices of attributes. The results are shown in Table 8. According to the test results of Poe et al., most of the ecological indicators have significantly different values for rural and urban residents except soil erosion area and natural landscape. The implicit price for forest coverage for urban residents is 30\% greater than for rural residents. This is probably because planting
TABLE 8: Poe et al. [29] test results for implicit prices derived from mixed logit models.

\begin{tabular}{lccc}
\hline $\begin{array}{l}\text { Ecological } \\
\text { indicators }\end{array}$ & $\begin{array}{c}P \\
\text { (urban-rural) }\end{array}$ & $\begin{array}{c}P \\
\text { (urban-pooled) }\end{array}$ & $\begin{array}{c}P \\
\text { (rural-pooled) }\end{array}$ \\
\hline Forest coverage & $0.0213^{* *}$ & 0.1254 & 0.1207 \\
Water quality & $0.0028^{* * *}$ & $0.0086^{* * *}$ & 0.2037 \\
Water quantity & $0.0098^{* * *}$ & $0.0592^{*}$ & 0.1600 \\
Erosion area & 0.2196 & 0.2840 & 0.3786 \\
Erosion intensity & $0.0012^{* * *}$ & $0.0304^{* *}$ & $0.0744^{*}$ \\
Landscape & 0.1573 & 0.4247 & 0.1794 \\
Tour & $0.0718^{*}$ & 0.4280 & $0.0674^{*}$ \\
\hline
\end{tabular}

Note: $*, * *$, and $* * *$ denote significance at $10 \%, 5 \%$, and $1 \%$ level, respectively.

more trees in the rural area will occupy farmers' croplands on which they normally cultivate wheat or corn for their livelihood. Landscape and tour are the only two indicators holding a higher implicit price value for rural residents than urban residents. Farmers are close to nature, and they greatly prefer a better environment to live in. A further main reason could be their hope of attracting urban residents to travel around the area. With regard to water and soil improvements, city residents value them more highly than farmers do. For instance, the implicit price values for water quantity and soil erosion intensity for urban residents are twice the values of rural residents.

\section{Discussion and Conclusions}

In this study, we have used a choice experiment to estimate nonmarket welfare for ecosystem services improvement in the Wei River basin in China. Residents' preferences for different ecological improvements were derived from household survey data and their behavior choices were analyzed to infer WTP. We tested residential environment induced preference heterogeneity by comparing WTP between urban and rural households.

It can be concluded that the restoration and improvement of all the ecological indicators of the Wei River ecosystem services can increase households' utility and engender their support. According to the results, all the marginal utility values derived from the mixed logit model (all respondents) 
and the calculated implicit price values show expected signs and are significant at 1\% level (Tables 6 and 7). However, the marginal utility values and implicit price values vary considerably across different ecological indicators. The ecological indicators with higher implicit price values should be viewed as priority items in policy making for the improvement of ecosystem services. In terms of the Wei River basin, the ecosystem services (such as water quality and soil erosion intensity) holding higher WTP values are supposed to be implemented as the most important items in basin governance, while landscape and ecotourism improvements should be implemented as subordinate items.

Demand divergence between different groups of people should also be taken into consideration in policy making. In this case study area, the Wei River basin, significant differences in the marginal WTP of different ecological indicators exist between urban and rural residents (Table 7). Respondents in both groups provided general consensus with regard to the implicit price of soil erosion area and landscape. However, they show heterogeneous preferences regarding the other ecological indicators (Table 8). The implicit price for forest coverage of the basin when valued by rural residents is only $63 \%$ of the value for urban residents, indicating a higher marginal WTP for urban households. Thus, urban greening construction should be promoted to increase total public support in the Wei River basin for ecological restoration. Generally, urban residents have higher implicit price values for most of the ecological indicators except for landscape and tour. Therefore, relevant policies, such as Payment for Ecosystem Services (PES), should take this heterogeneity into account for maximum welfare benefit from ecological restoration and to balance the allocation of resources between urban and rural households.

Given the results of our study, we can draw the following policy implications: the marginal utility residents derive from ecological restoration policies (Wei River basin governance as in this case study) as measured by the WTP for each ecological attribute varies significantly between different urban and rural residents in China, probably due to the gap in the economic and environmental indicators of their respective living areas. The prevailing residential related preference heterogeneity between urban and rural households should be taken into consideration when relevant ecological restoration policies are designed. Recently, the state council of China has launched the Water Pollution Control Action Plan (WPCAP) with a two-trillion-Yuan investment to achieve substantial improvements in water and environmental quality. (The Water Pollution Control Action Plan is launched in April 2015. Details with ten items can be checked on the website of the Central People's Government of China (http://www.gov.cn/zhengce/content/2015-04/16/content_9613.htm).) WPCAP stresses the importance of public participation in water and environmental protection but has failed to note the public preference heterogeneity for ecosystem service improvements, especially the difference in demand between urban and rural households. The findings of the present research are therefore expected to provide policy makers with useful nonattended information for the management of ecosystem services.
Moreover, the estimated WTP for the ecological indicators and their assigned levels can be used in the cost benefit analyses of different restoration strategies in the basin and other regions. The values provide references for related research into applied benefit transfer methods, making them cheaper and more convenient, and for undertaking welfare valuation of analogous watersheds ecosystem services.

\section{Conflict of Interests}

The authors declare that there is no conflict of interests regarding the publication of this paper.

\section{Acknowledgments}

The survey was sponsored by "Multiobjective Decision of Water Allocation in Northwest China: Quantifying Full Values and the Public Support (no. 71373209, 2014.1-2017.12)," "Construction of Natural Resources Management System under the Background of Ecological Civilization: Full Values and Multicenter Approach (no. 15ZDA052, 2015.7-2017.6)," and "Doctoral Dissertation Scholarship of China Institute for Rural Studies, Tsinghua University (no. 201518, 2015.122016.6)."

\section{References}

[1] R. S. Yin, An Integrated Assessment of China's Ecological Restoration Programs, Springer, Dordrecht, The Netherlands, 2009.

[2] Z. T. Wu, J. J. Wu, J. H. Liu, B. He, T. Lei, and Q. F. Wang, "Increasing terrestrial vegetation activity of ecological restoration program in the Beijing-Tianjin Sand Source Region of China," Ecological Engineering, vol. 52, pp. 37-50, 2013.

[3] M. Chen, X. Qian, and L. J. Zhang, "Public participation in environmental management in China: status quo and mode innovation," Environmental Management, vol. 55, no. 3, pp. 523$535,2015$.

[4] W. Lu, N. Landell-Mill, J. Liu, J. Xu, and C. Liu, Getting the Private Sector to Work for the Public Good, International Institute for Environment and Development, London, UK, 2002.

[5] X. H. Wang, J. Bennett, C. Xie, Z. T. Zhang, and D. Liang, "Estimating non-market environmental benefits of the conversion of cropland to forest and grassland program: a choice modeling approach," Ecological Economics, vol. 63, no. 1, pp. 114-125, 2007.

[6] MA (Millennium Ecosystem Assessment), Ecosystems and Human Well-being: Synthesis, Island Press, Washington, DC, USA, 2005.

[7] J. Y. Lin and B. K. Chen, "Urbanization and urban-rural inequality in China: a new perspective from the government's development strategy," Frontiers of Economics in China, vol. 6, no. 1, pp. 1-21, 2011.

[8] E. Birol, K. Karousakis, and P. Koundouri, "Using a choice experiment to account for preference heterogeneity in wetland attributes: the case of Cheimaditida wetland in Greece," Ecological Economics, vol. 60, no. 1, pp. 145-156, 2006.

[9] S. Colombo, N. Hanley, and J. Louviere, "Modeling preference heterogeneity in stated choice data: an analysis for public goods generated by agriculture," Agricultural Economics, vol. 40, no. 3, pp. 307-322, 2009. 
[10] R. Brouwer, J. Martin-Ortega, and J. Berbel, "Spatial preference heterogeneity: a choice experiment," Land Economics, vol. 86, no. 3, pp. 552-568, 2010.

[11] J. Abildtrup, S. Garcia, S. B. Olsen, and A. Stenger, "Spatial preference heterogeneity in forest recreation," Ecological Economics, vol. 92, pp. 67-77, 2013.

[12] Y. Wang, M. Zhang, H. Gong, and S. C. Zhang, "The main points of the Wei River Key Governance Plan," Yellow River, vol. 28, no. 6, pp. 63-64, 2006.

[13] K. J. Lancaster, "A new approach to consumer theory," The Journal of Political Economy, vol. 74, no. 2, pp. 132-157, 1966.

[14] L. L. Thurstone, "A law of comparative judgment," Psychological Review, vol. 34, no. 4, pp. 273-286, 1927.

[15] D. McFadden, "The measurement of urban travel demand," Journal of Public Economics, vol. 3, no. 4, pp. 303-328, 1974.

[16] C. F. Manski, "The structure of random utility models," Theory and Decision, vol. 8, no. 3, pp. 229-254, 1977.

[17] J. I. Yellott Jr., “The relationship between Luce's choice axiom, Thurstone's theory of comparative judgment, and the double exponential distribution," Journal of Mathematical Psychology, vol. 15, no. 2, pp. 109-144, 1977.

[18] M. E. Ben-Akiva and S. R. Lerman, Discrete Choice Analysis: Theory and Application to Travel Demand, vol. 9, MIT Press, 1985.

[19] D. Revelt and K. Train, "Mixed logit with repeated choices: households' choices of appliance efficiency level," Review of Economics and Statistics, vol. 80, no. 4, pp. 647-657, 1998.

[20] D. Brownstone, D. S. Bunch, and K. Train, "Joint mixed logit models of stated and revealed preferences for alternative-fuel vehicles," Transportation Research Part B: Methodological, vol. 34, no. 5, pp. 315-338, 2000.

[21] G. Daily, Ed., Nature's Services: Societal Dependence on Natural Ecosystems, Island Press, 1997.

[22] R. Costanza, R. d'Arge, R. De Groot et al., "The value of the world's ecosystem services and natural capital," Nature, vol. 387, no. 6630, pp. 253-260, 1997.

[23] R. de Groot, J. van der Perk, A. Chiesura, and S. Marguliew, "Ecological functions and socioeconomic values of critical natural capital as a measure for ecological integrity and environmental health," in Implementing Ecological Integrity, pp. 191-214, Springer, Amsterdam, The Netherlands, 2000.

[24] W. F. Kuhfeld, "Marketing research methods in SAS: experimental design, choice, conjoint, and graphical techniques," SAS Document TS-694, 2005.

[25] Z. Gao, L. O. House, and X. Yu, "Using choice experiments to estimate consumer valuation: the role of experimental design and attribute information loads," Agricultural Economics, vol. 41, no. 6, pp. 555-565, 2010.

[26] K. E. Train, Discrete Choice Methods with Simulation, Cambridge University Press, Cambridge, UK, 2003.

[27] A. R. Hole, "Estimating mixed logit models using maximum simulated likelihood," The Stata Journal, vol. 7, no. 3, pp. 388401, 2007.

[28] D. A. Hensher and W. H. Greene, "The mixed logit model: the state of practice," Transportation, vol. 30, no. 2, pp. 133-176, 2003.

[29] G. L. Poe, K. L. Giraud, and J. B. Loomis, "Simple computational method for measuring the differences of empirical distributions: application to internal and external scope tests in contingent valuation," Staff Paper 2001-2005, Department of Agricultural, Resource and Managerial Economics, Cornell University, Ithaca, NY, USA, 2001. 


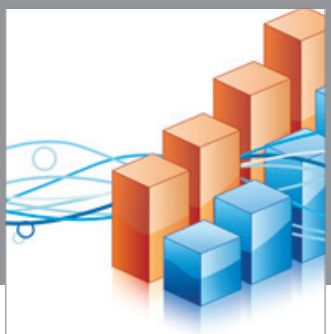

Advances in

Operations Research

vatem alat4

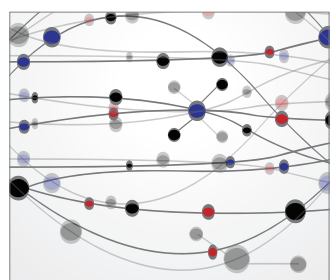

\section{The Scientific} World Journal
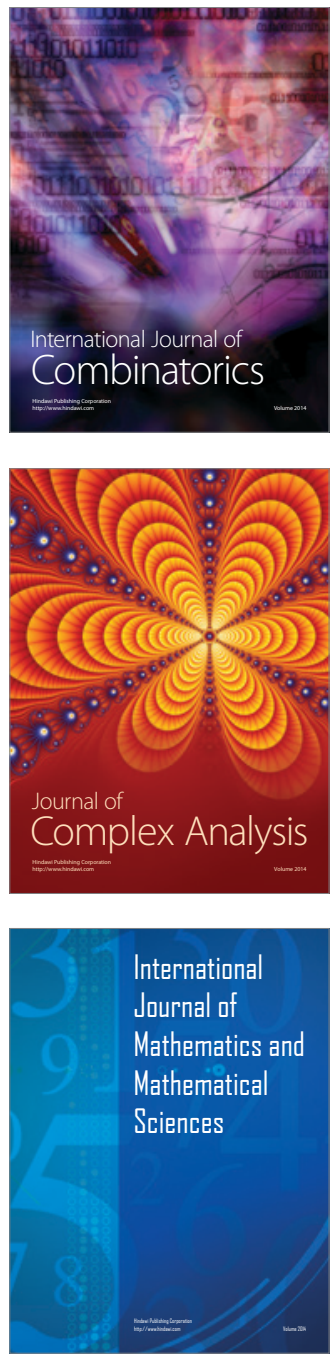
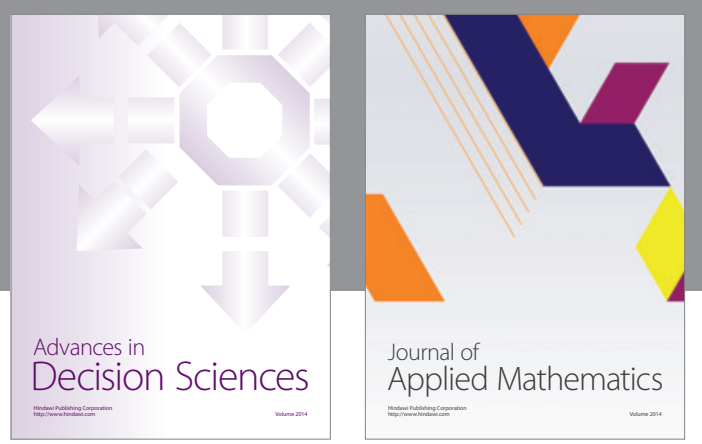

Algebra

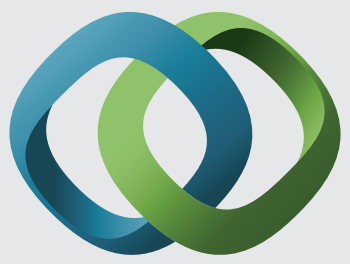

\section{Hindawi}

Submit your manuscripts at

http://www.hindawi.com
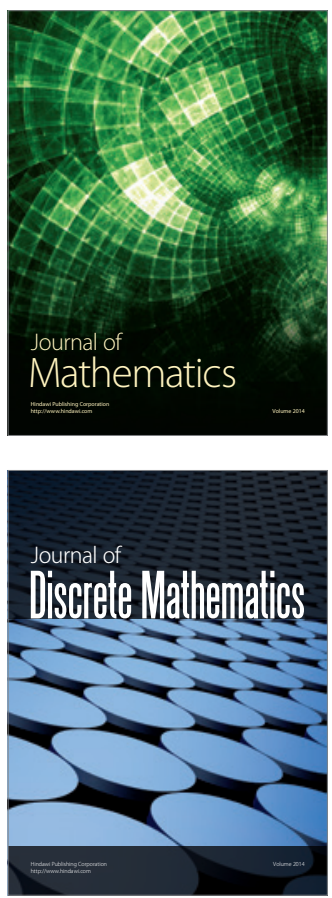

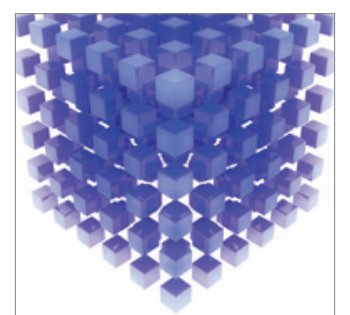

Mathematical Problems in Engineering
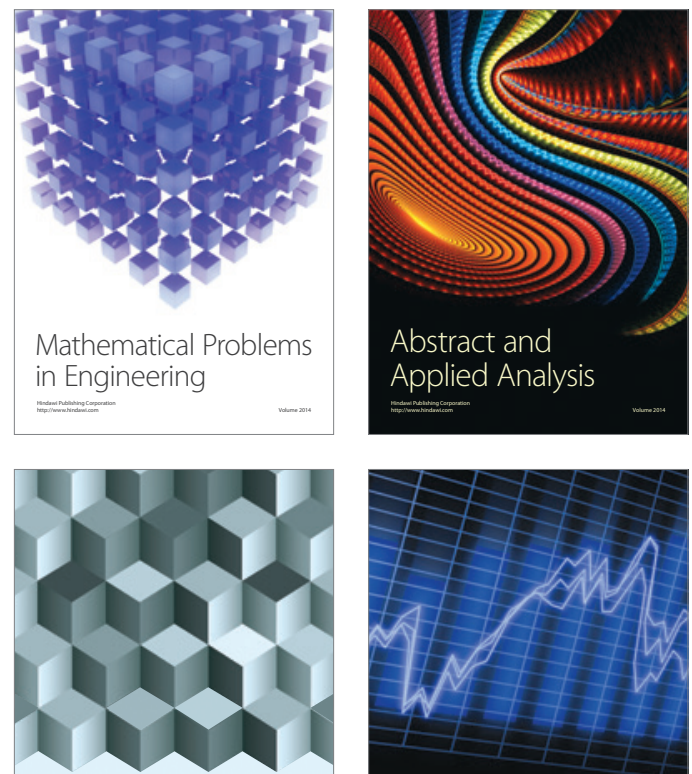

Journal of

Function Spaces

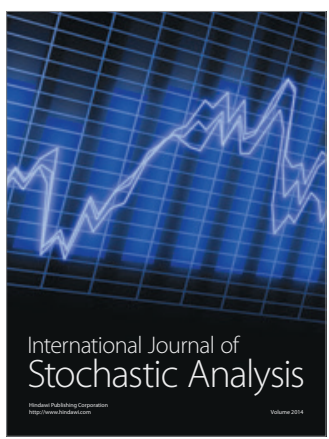

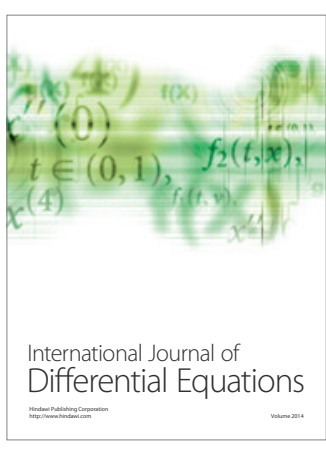
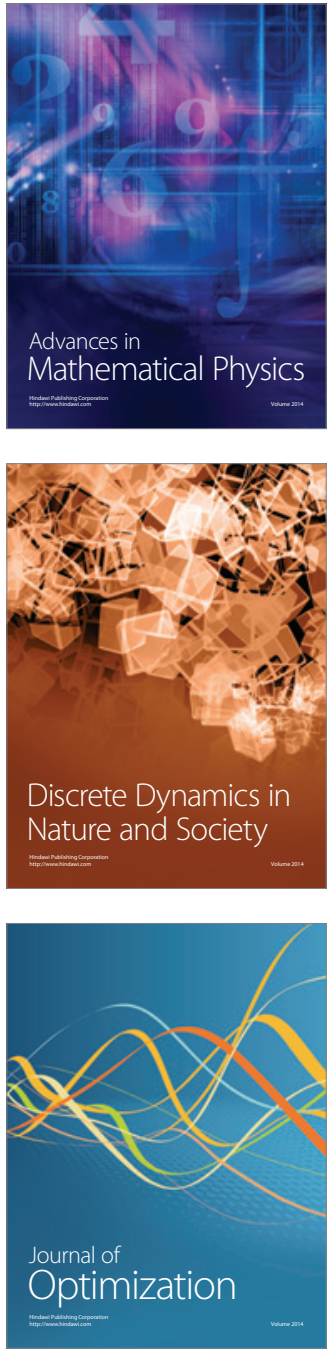